\title{
Molluscicidal activities of Ginkgo biloba leaf against the snail Oncomelania hupensis
}

\author{
Yuan-yuan $\mathrm{Li}^{1}$, Jun Chen ${ }^{1 *}$, Bang-xing Han ${ }^{1,2}$, Guo-bo Pan ${ }^{3}$ and Dan-zhao Guo ${ }^{1,4}$ \\ ${ }^{1}$ School of Pharmacy, Jiangsu University, Zhenjiang 212013, P. R. China. \\ ${ }^{2}$ Research Center of Plant Cell Engineering of Anhui Province, Lu'an, 237012, P. R. China. \\ ${ }^{3}$ School of Chemistry and Chemical Engineering, Jiangsu University, Zhenjiang 212013, P. R. China. \\ ${ }^{4}$ College of Life science and technology, Henan Institute of Science and Technology, Henan, P. R. China
}

Accepted 2 August, 2010

\begin{abstract}
In search for new plant molluscicides that could be used to control schistosomiasis, the ethanolic and aqueous extracts of five medicinal plants: Ginkgo biloba, Torreya grandis, Ailanthus altissima, Peucedanum praerutorum and Herba agrimoniae from China were obtained to evaluate their molluscicidal activity against the snail Oncomelania hupensis. In all of the plant extracts, only the ethanolic extract of fallen leaf from G. biloba showed the highest toxicity on the snails within $48 \mathrm{~h}$ exposure. The petroleum ether fraction of ethanolic extract of fallen leaf from G. biloba (PFGB) showed significant activity against the snails and also revealed the time and dose dependent effect. Statistical analysis revealed that the $L C_{50}$ values of PFGB was decreased from $72.38 \mathrm{mg} \cdot \mathrm{L}^{-1}(24 \mathrm{~h})$ to $9.22 \mathrm{mg} \cdot \mathrm{L}^{-1}(72$ h). Whereas, the $L C_{50}$ values of PFGB to zebra fish was $131.34 \mathrm{mg} \cdot \mathrm{L}^{-1}$. The glycogen and total protein content of soft tissues of snails decreased after treated with PFGB, and the decreasing rate was parallel to the molluscicidal activity. Therefore, the petroleum ether fraction of ethanolic extract of the fallen leaf from G. biloba exhibited promising molluscicidal activity against the snail and might be a potent molluscicides.
\end{abstract}

Key words: Ginkgo biloba, molluscicidal activity, Oncomelania hupensis, glycogen, total protein.

\section{INTRODUCTION}

Schistosomiasis is one of the most prevalent parasitic infections and has significant economic and public health consequences (Chitsulo et al., 2000; Engels et al., 2002). It is estimated that 200 million people are infected with $S$. trematodes in many parts of the developing world, such as Africa, Asia, and tropical America, where 120 million are symptomatic and 20 million have severe disease (WHO, 1984; Allen and Victory, 2003). In China, Schistosomiasis caused by Schistosoma japonicum is epidemic in the Southeast, especially in the areas of Yangtze River valley (Zhou et al., 2005). Oncomelania hupensis, is the only intermediate host of $S$. japonicum which is the species in China causing schistosomiasis. In order to control this disease, one efficient way is to attack and break down the life cycle of $S$. japonicum.

\footnotetext{
${ }^{*}$ Corresponding author. E-mail: syxchenjun@126.com. Tel: +86 51188780196 . Fax: +86 51188780196.
}

Niclosamide (the only commercially available molluscicide recommended by the World Health Organization) has been used extensively over the years, especially in schistosomiasis control programmes. However, it is highly toxic to non-target organisms such as fish, amphibian and aquatic plants (Pieri et al., 1995; Andrews et al., 1983). Therefore, there has been a renewed interest in finding cheaper, environmentally friendly and readily available natural molluscicidal compounds from plants alternative to synthetic products used in snail control.

Many countries search for safe and low-cost molluscicides by using the naturally occurring plants that can be applied effectively in different habitats, and a large number of plant products with molluscicidal activity have been identified (Preetee and Singh, 2008; Adedotun and Alexander, 2008). Examples are Arisaema erubescens, Nerium indicum and Cinnamomum camphora (Ke et al., 2008; Liu et al., 2006). Ginkgo biloba is one of the oldest living tree species in China, dating back over 300 million years. As a traditional Chinese herbal medicine, it has 
been used for 5 thousand years to treat lung ailments such as asthma bronchitis (Bruce, 2000). Recently, it has been reported that ginkgolic acids in Ginkgo sarcotesta extracts has molluscicidal activity against $O$. hupensis (Yang et al., 2008). But to our knowledge, molluscicidal activities of Ginkgo leaf are not reported. Therefore, previous studies stimulate our interest in finding whether there is molluscicidal activity in leaf from $G$. biloba. Ginkgo leaf contains many bioactive compounds, including flavonol and flavone glycosides, terpenoids and ginkgolides (Thanh et al., 2001).

They have beneficial effects in the treatment of cerebrovascular insufficiency and peripheral circulatory problems (Schäfer et al., 2006). However, ginkgolic acids and related alkylphenols have been identified as potentially hazardous constituents in Ginkgo leaf extracts and do not contribute to the therapeutic action (Barbara et al., 2001). Furthermore, in order to protect the environment and make full use of resources, we have researched in fallen leaf of $G$. biloba and it might play a significant role in prevention and treatment of schistosomiasis.

In the present study we evaluated molluscicidal activity of fallen leaf from $G$. biloba against the snail $O$. hupensis. The aims of this research are to find out the molluscicidal activity of other parts of $G$. biloba and make comprehensive utilization of $G$. biloba leaf not only confined to the clinical treatment but also used for snail control, turning fallen leaf into treasure.

\section{MATERIALS AND METHODS}

\section{Source of snails}

The snails (Oncomelania hupensis) with relatively uniform in size (8 - $10 \mathrm{~mm}$ ) were collected from the beach of Yangtze River near Zhenjiang in Jiangsu province of China, and acclimatized in the laboratory at room temperature $\left(25 \pm 1^{\circ} \mathrm{C}\right)$ for 2 - 3 days.

\section{Plant materials}

G biloba leaf, Torreya grandis leaf, Ailanthus altissima leaf, Peucedanum praerutorum root and Herba agrimoniae herb were collected in Jiangsu province, China in November 2009 and identified by Prof. Jun Chen of the Pharmacognosy Laboratory, School of Pharmaceutical. Voucher specimens are deposited in the Pharmacognosy Laboratory, School of Pharmacy, Jiangsu University.

\section{Efficacy in traditional medicine}

G biloba is used for the treatment of cerebrovascular insufficiency and peripheral circulatory problems (Schäfer et al., 2006). The leaf extract of $G$ biloba could reduce blood pressure, blood glucose and showed anti-oxidant activity (Lena et al., 2003). T. grandis is used against cough and lung diseases, and the leaf extract presented antinociceptive and anti-inflammatory activity (Muhammad et al., 2010). A. altissima is used for curing diarrhoea and healing wounds. The leaf extract of $A$. altissima showed anti-tumour, anti-virus, anti- bacteria and anti-amoebas activity (Tan et al., 2008). $P$. praerutorum seed is used as anti-asthma and remedy against angina (Schillaci et al., 2003). The herb extract of $H$. agrimoniae presented anti-tumour, anti- inflammatory and antiarrhythmic activity (Hong et al., 2008).

\section{Preparation of extracts}

Following collection, all of the plant materials were air dried and then crushed into fine powder. The particle size of powder was controlled below 40 meshes. Fifty grams each of the powdered plant material was extracted separately with reflux using $95 \%$ ethanol $(0.5 \mathrm{~L})$ and water $(0.5 \mathrm{~L})$ for $24 \mathrm{~h}$ and then filtered. The filter residue was extracted twice more in the same way. The filtrates were combined and then evaporated under reduced pressure in a rotary evaporator to obtain ethanolic extracts and aqueous extracts, respectively. Ethanolic and aqueous extracts of tested materials were stored in a freezer at $-20^{\circ} \mathrm{C}$ until required.

The ethanolic extract of $G$. biloba leaf was dissolved by water and then extracted by different solvents in the sequence of petroleum ether, diethyl ether, ethyl acetate and n-butanol saturated by water. Finally, the petroleum ether fraction (PFGB), diethyl ether fraction (DFGB), ethyl acetate fraction (EFGB) and n-butanol fraction (NFGB) were obtained. Fractions were stored in a freezer at $-20^{\circ} \mathrm{C}$ until required. Each fraction was diluted with an appropriate volume of dechlorinated water in order to provide assay solution as required.

\section{Molluscicidal activity assay of the extracts}

Molluscicidal activitity of the extracts against $O$. hupensis were determined according to the standard WHO guidelines (Chen et al., 2009). At room temperature $\left(25 \pm 1^{\circ} \mathrm{C}\right), 30$ snails were put into a nylon net bag ( $5 \mathrm{~cm}$ in diameter). Three bags were immerged in beakers containing $900 \mathrm{ml}$ of the test solutions. Negative control groups were immerged in de-chlorinated water and positive control groups were treated with $1 \mathrm{ppm}$ of Niclosamide. After 24, 48, $72 \mathrm{~h}$ of exposure, test snails were washed with de-chlorinated water for 5 times and then kept in de-chlorinated water for another $24 \mathrm{~h}$ for recovery. The snails climbing upwards the wall of beakers were judged to be alive, and the snails remained in the bottom of beakers were further examined to check mortality by mechanical prodding. Each test was set in triplicate. The ratio of dead snails to total tested snails was expressed as mortality (\%).

\section{Molluscicidal active fractions of ethanolic extract from Ginkgo biloba}

In order to further confirm molluscicidal active fractions, $5 \mathrm{mg} \cdot \mathrm{L}^{-1}$ of the five fractions (PFGB, DFGB, EFGB, NFGB and remaining fraction) of ethanolic extract of Ginkgo biloba leaf were used to treat the snails. Every 30 snails, as one group, were immerged in beakers containing the test solutions. Snails were exposed to the molluscicide solution for 24,48 and $72 \mathrm{~h}$ respectively. PFGB was dissolved in DMF for hydrotropy. Reagent control groups were immerged in $1 \%$ DMF de-chlorinated water solution. Negative control groups were immerged in de-chlorinated water and positive control groups were treated with $1 \mathrm{ppm}$ of Niclosamide. Each test was set in triplicate.

Dose dependent of climbing upwards snails in petroleum ether fraction

Every 30 snails, as one group, were exposed to a dilution series of 
Table 1. Plants employed in this study and the activities of ethanolic extracts and aqueous extracts against Oncomelania hupensis $(\mathrm{n}=3)(\mathrm{M} \pm \mathrm{SD})$.

\begin{tabular}{|c|c|c|c|c|c|}
\hline \multirow{2}{*}{ Species } & \multirow{2}{*}{ Part used } & \multirow{2}{*}{ solvents } & \multicolumn{3}{|c|}{ Mortality (\%) with different time } \\
\hline & & & $24 \mathrm{~h}$ & $48 \mathrm{~h}$ & $72 \mathrm{~h}$ \\
\hline \multirow{2}{*}{ Ginkgo biloba } & \multirow{2}{*}{ Leaf } & Ethanolic & $80.00 \pm 10.00$ & $93.33 \pm 5.77$ & 100.00 \\
\hline & & Water & $6.67 \pm 11.55$ & $40.00 \pm 10.00$ & $83.33 \pm 5.77$ \\
\hline \multirow[b]{2}{*}{ Torreya grandis } & \multirow[b]{2}{*}{ Leaf } & Ethanolic & $10.00 \pm 10.00$ & $43.33 \pm 5.77$ & $80.00 \pm 10.00$ \\
\hline & & Water & $3.33 \pm 5.77$ & $23.33 \pm 15.28$ & $63.33 \pm 11.55$ \\
\hline \multirow{2}{*}{ Ailanthus altissima } & \multirow{2}{*}{ Leaf } & Ethanolic & $3.33 \pm 5.77$ & $26.67 \pm 5.77$ & $40.00 \pm 10.00$ \\
\hline & & Water & $6.67 \pm 5.77$ & $20.00 \pm 10.00$ & $33.33 \pm 5.77$ \\
\hline \multirow{2}{*}{ Peucedanum praerutorum } & \multirow{2}{*}{ Root } & Ethanolic & $6.67 \pm 5.77$ & $36.67 \pm 5.77$ & $83.33 \pm 5.77$ \\
\hline & & Water & $3.33 \pm 5.77$ & $23.33 \pm 5.77$ & $76.67 \pm 5.77$ \\
\hline \multirow{2}{*}{ Herba agrimoniae } & \multirow{2}{*}{ Herb } & Ethanolic & $3.33 \pm 5.77$ & $30.00 \pm 10.00$ & $80.00 \pm 10.00$ \\
\hline & & Water & 0 & $16.67 \pm 5.77$ & $40.00 \pm 10.00$ \\
\hline Dechlorinated water & & & 0 & 0 & 0 \\
\hline Niclosamide & & & 100 & 100 & 100 \\
\hline
\end{tabular}

All extracts tested at a concentration of $100 \mathrm{mg} \cdot \mathrm{L}^{-1}$, Niclosamide at a concentration of $1 \mathrm{mg} \cdot \mathrm{L}^{-1}$.

$2,4,6,8,10 \mathrm{mg} \cdot \mathrm{L}^{-1}$ of the petroleum ether fraction for $24 \mathrm{~h}$. The climbing upwards snails to tested total snails was expressed as rate of climbing (\%). Each test was set in triplicate.

\section{Glycogen (Gn) and Total protein (TPr) assay}

PFGB was prepared at two concentrations of 28.95 and $57.9 \mathrm{mg} \cdot \mathrm{L}^{-1}$ respectively with dechlorinated water, which were 40 and $80 \%$ of the $\mathrm{LC}_{50}$ values. Then they were used to treat the snail $O$. hupensis. The negative group was performed with the dechlorinated water only. Snails were randomly and equally divided into 3 groups. Every 60 snails, as one group, were submerged in beakers containing the test solutions. Each test was set in triplicate. After being immersed for $24 \mathrm{~h}$, the snails were washed with dechlorinated water, and then left in dechlorinated water, the climbing upwards snails were taken out from the beaker and the soft tissue of each snail was obtained after removing the shell. Then their soft tissues were dried in oven for $24 \mathrm{~h}$ at $40^{\circ} \mathrm{C}$, and the dried soft tissues were grounded into fine powder for $\mathrm{Gn}$ and Tpr assay.

About $10 \mathrm{mg}$ of the soft tissue powder was weighed and encased in the test tube, then $2 \mathrm{ml}$ solution of $30 \% \mathrm{KOH}$ was added to the tube and incubated in a boiling water bath for 20 min. After incubating, the test tube was cooled to room temperature. Finally $10 \mathrm{ml}$ ethanol was added, and the precipitate (namely $\mathrm{Gn}$ ) was got by centrifuging at $2000 \mathrm{r} / \mathrm{min}$ for $10 \mathrm{~min}$. Gn content was analyzed by anthrone-colorimetric method.

Approximately $100 \mathrm{mg}$ of the soft tissue powder was used for Tpr assay, and TPr content was detected with KND-04 Kjeldahl nitrogen detection device. The Tpr content was calculated as: $(\operatorname{TPr}) \%=$ $6.25 \times \mathrm{N} \%$.

\section{Acute toxicity of PFGB to zebra fish}

Zebra fish were exposed to a concentration series of $80,100,120$, 140,160 and $180 \mathrm{mg} \cdot \mathrm{L}^{-1}$ for $48 \mathrm{~h}$. Each concentration of ten zebra fish was placed in a plastic drum containing $5 \mathrm{~L}$ solution of PFGB. Negative control groups were immerged in de-chlorinated water and positive control groups were treated with $1 \mathrm{ppm}$ of Niclosamide. Temperature during the test period was set at $25 \pm 1^{\circ} \mathrm{C}$. Each test was set in triplicate. During the experiment zebra fish were not fed and the dead ones were removed from solutions. The ratio of dead zebra fish to total tested zebra fish was expressed as mortality (\%).

\section{Statistical analysis}

The molluscicidal activity test data were statistically analyzed by SPSS17.0. The effect of the plant extracts on $O$. hupensis was expressed by $\mathrm{LC}_{50}$ and $\mathrm{LC}_{90}$ and the result was expressed as $\mathrm{M} \pm$ $\mathrm{SD}$. The $\mathrm{LC}_{50}$ and $\mathrm{LC}_{90}$ values were calculated by the probit analysis. One way ANOVA was applied to locate significant differences $(p<0.05)$.

\section{RESULTS AND DISCUSSION}

\section{Molluscicidal activity of the plant extracts}

A total of ten plant extracts of various parts from five medicinal plants (G. biloba, T. grandis, A. altissima, $P$. praerutorum and $H$. agrimoniae) were tested for molluscicidal activity and the results were shown in (Table 1). Snails were exposed to the molluscicide solution for 24 , 48 and $72 \mathrm{~h}$ at concentrations of $100 \mathrm{mg} \cdot \mathrm{L}^{-1}$. In all of the ten plant extracts, five ethanolic extracts were more effective than the five aqueous extracts towards adult snails within $72 \mathrm{~h}$ exposure. In the five ethanolic extracts, the ethanolic extract of $G$. biloba leaf showed the highest toxicity on snails after treated for $48 \mathrm{~h}$. In addition, it also showed moderate toxicity towards snails within $24 \mathrm{~h}$ exposure, the mortality (\%) values was $80.00 \pm 10.00 \%$. Therefore, we focus attention to the ehanolic extract of $G$. biloba leaf.

\section{Screening of molluscicidal active fractions of $G$. biloba leaf}

In search for active fractions of G biloba leaf, five 


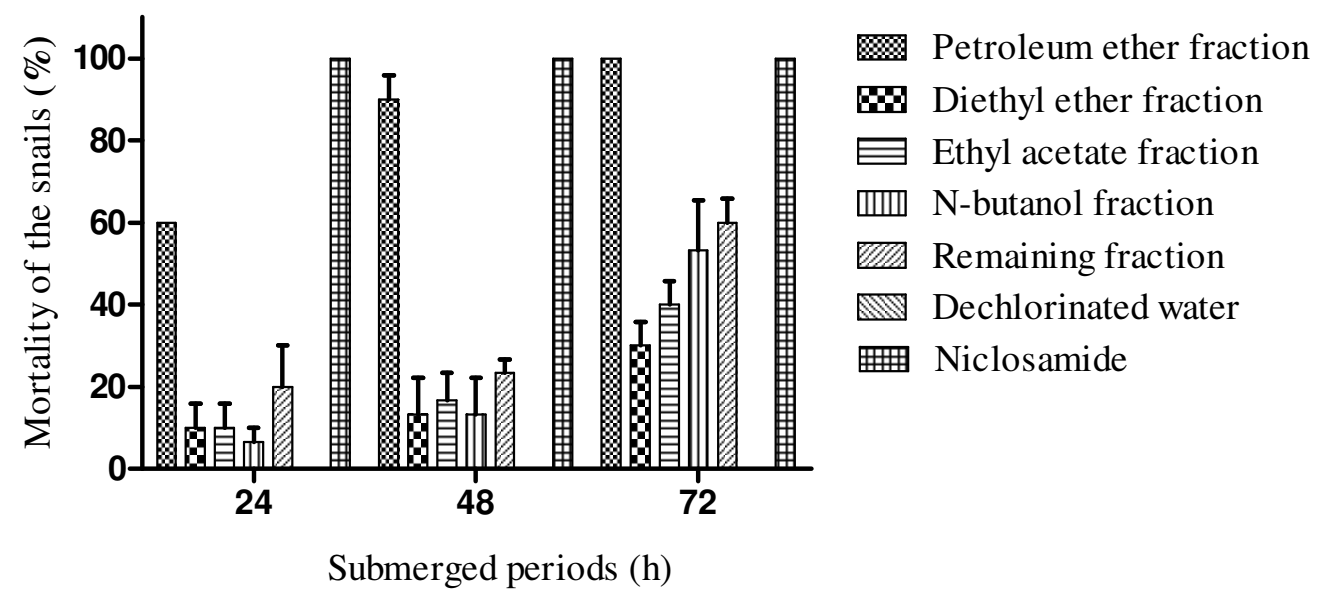

Figure 1. Different fractions of Ginkgo biloba leaf against Oncomelania hupensis $(n=3)$. Fractions tested at a concentration of $5 \mathrm{mg} \cdot \mathrm{L}^{-1}$, Niclosamide at a concentration of $1 \mathrm{mg} \cdot \mathrm{L}^{-1}$.

Table 2. The mortality of snails treated by PFGB $(n=3)(M \pm S D)$.

\begin{tabular}{cccc}
\hline \multirow{2}{*}{ Dose $\left(\mathbf{m g} \cdot \mathrm{L}^{-1}\right)$} & \multicolumn{3}{c}{ Mortality (\%) with different time } \\
\cline { 2 - 4 } & $\mathbf{2 4} \mathbf{~ h}$ & $\mathbf{4 8} \mathbf{~ h}$ & $\mathbf{7 2} \mathbf{~ h}$ \\
\hline 2.1875 & & $3.33 \pm 5.77$ & $10.00 \pm 10.00$ \\
4.375 & & $30.00 \pm 10.00$ & $43.33 \pm 5.77$ \\
8.75 & & $43.33 \pm 5.77$ & $56.67 \pm 11.55$ \\
17.5 & & $56.67 \pm 5.77$ & $73.33 \pm 5.77$ \\
35 & & $96.67 \pm 5.77$ & 100 \\
8.75 & $6.67 \pm 5.77$ & & \\
17.5 & $30.00 \pm 10.00$ & & \\
35 & $43.33 \pm 5.77$ & & \\
70 & $56.67 \pm 5.77$ & & \\
140 & $73.33 \pm 5.77$ & & \\
CC $_{50}$ & 72.38 & 13.78 & 9.22 \\
CC $_{90}$ & 180.14 & 28.67 & 21.86 \\
\hline
\end{tabular}

Mortality for dechlorinated tap water and $1 \%$ DMF control groups were $0 \%$, and the mortality for $1 \mathrm{mg} \cdot \mathrm{L}^{-1}$ of Niclosamide was $100 \%$ for the test time.

fractions of ethanolic extract of $G$. biloba leaf (PFGB, DFGB, EFGB, NFGB and remaining fraction) were assayed for molluscicidal activity. The mortality (\%) values were shown in (Figure 1). The molluscicidal activity of PFGB was more pronounced than other fractions and also showed time dependent effect. PFGB showed medium toxicity towards snails within $24 \mathrm{~h}$ exposure, and the mortality values was $60 \%$. When increasing exposure time to $72 \mathrm{~h}$, it showed $100 \%$ mortality at concentrations of $5 \mathrm{mg} \cdot \mathrm{L}^{-1}$. Molluscicidal activity of other fractions was faint even if increasing the exposure time to $72 \mathrm{~h}$. In contrast, the 1\% DMF reagent control groups and de-chlorinated water negative control groups did not exhibit any molluscicidal activity in whole exposure periods. Therefore, we get PFGB as molluscicidal active fraction of $G$. biloba leaf.

\section{Molluscicidal activity of PFGB}

In order to further ascertain molluscicidal activity, the calculated $L_{50}$ and $L_{90}$ values of PFGB for snails were given in (Table 2). PFGB showed significant activity against $O$. hupensis and it also revealed time and dose dependent effects. The dead numbers of snails increased with increase of PFGB concentration and exposure time. 


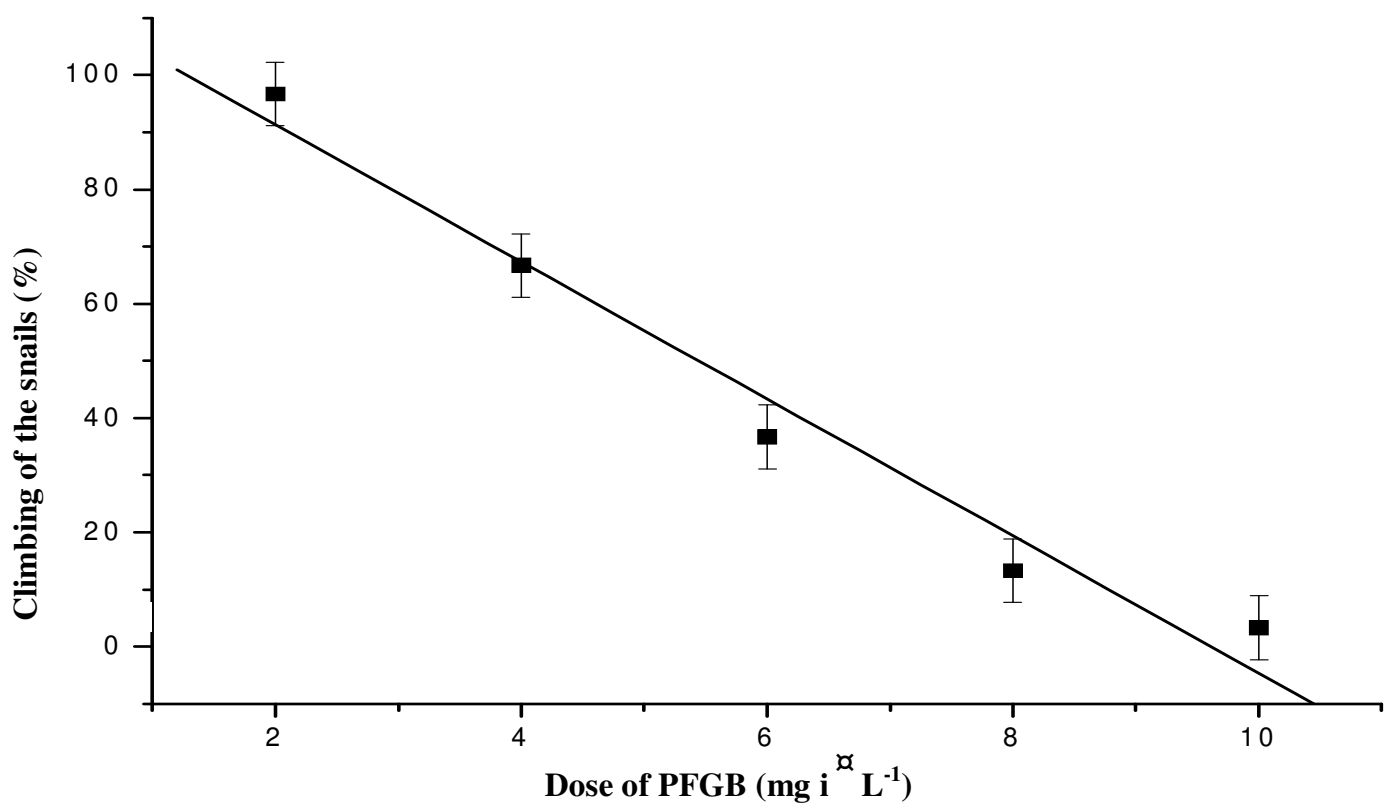

Figure 2. Dose dependent between PFGB and climbing of the snails $(n=3)$.

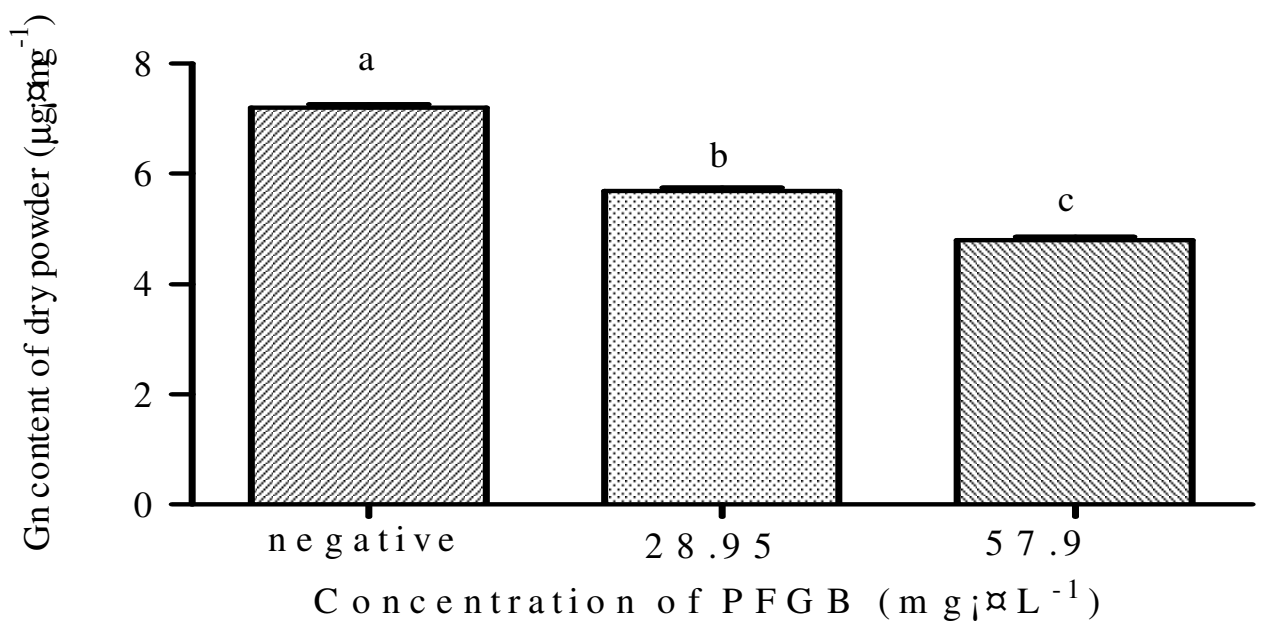

Figure 3. Gn content of soft tissues of snails treated by PFGB $(n=3)$. The difference between averages with different letters was significant $(P \leq 0.05)$

When increasing the exposure time, the $\mathrm{LC}_{50}$ values of the PFGB was decreased from $72.38 \mathrm{mg}^{-1} \mathrm{~L}^{-1}(24 \mathrm{~h})$ to $9.22 \mathrm{mg}^{\cdot L^{-1}}(72 \mathrm{~h})$ against $O$. hupensis. It is the same to the $\mathrm{LC}_{90}$ values, with the increase of the exposure time, the $L_{90}$ values was decreased from $180.14 \mathrm{mg} \cdot \mathrm{L}^{-1}(24 \mathrm{~h})$ to $21.86 \mathrm{mg} \cdot \mathrm{L}^{-1}$ (72 h).

At the same time, there was a significant negative correlation between climbing upwards snails and dose (Figure 2). When increasing the dose, the rate of climbing (\%) was decreased from $96.67 \%$ to $3.33 \%$. The linear regression between climbing upwards snails and dose is as follows: $Y=115.3-12 \times\left(R^{2}=0.9708\right)$.

\section{Gn and TPr content of snails' soft tissues tested}

To preliminarily study the mechanism of PFGB in snail controlling, the Gn and TPr content of snails' soft tissues were analyzed, and the calculated results were as follows. The results indicated that the $\mathrm{Gn}$ content decreased greatly after treat with PFGB, ranging from $14-22 \%$ (Figure 3). The TPr content also decreased after treatments, but it was not obvious, ranging from 1.9 $3.2 \%$ (Figure 4). The $\mathrm{Gn}$ and Tpr decreasing rate were parallel to the molluscicidal activity. The stronger the molluscicidal activity, the more decrease in Gn content 


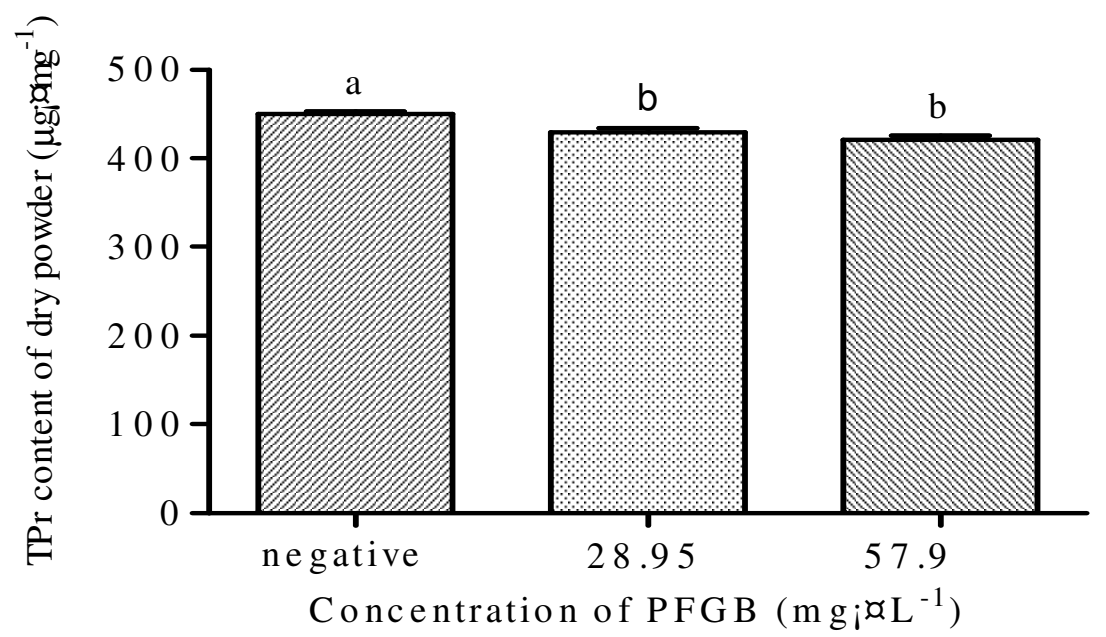

Figure 4. TPr content of soft tissues of snails treated by PFGB $(n=3)$. The difference between averages with a same letter was not significant $(P \geq 0.05)$, and the difference between averages with different letter was significant $(P \leq 0.05)$

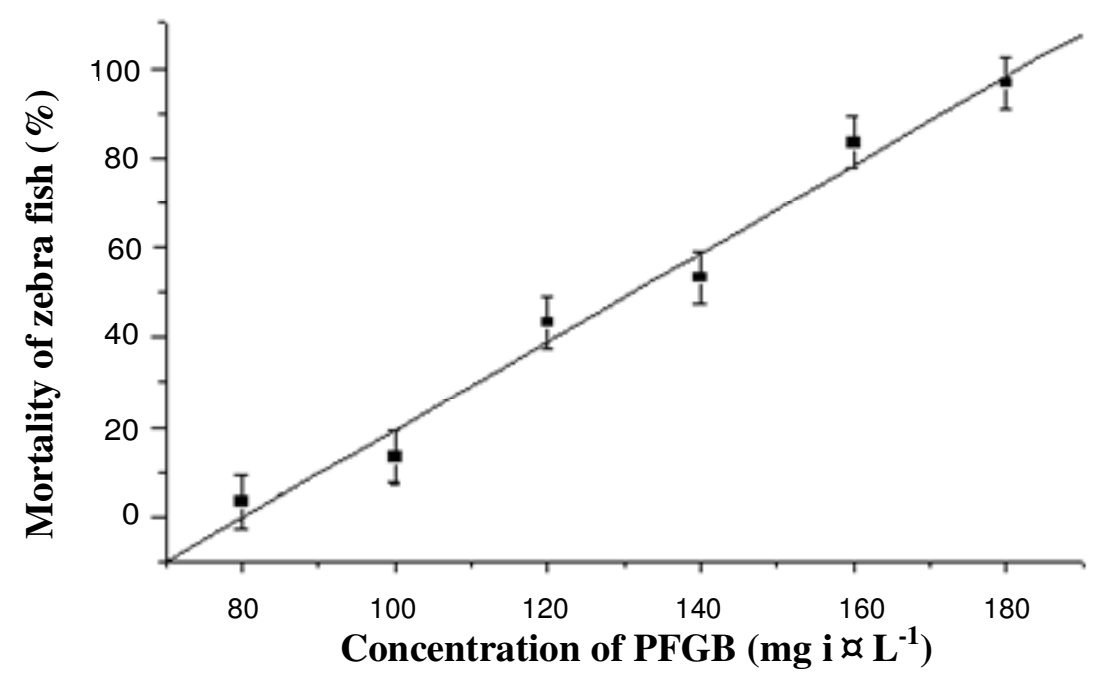

Figure 5. Dose dependent between PFGB and mortality of zebra fish $(n=3)$.

and TPr content. PFGB can decrease the $\mathrm{Gn}$ and TPr content in snails' soft tissues, and it suggests that the abnormity of energy metabolism might be a factor for the molluscicidal activity.

\section{Acute toxicity of PFGB to zebra fish}

In our present research, zebra fish toxicity test was used for evaluating toxicity of PFGB on non target organisms. The results showed that PFGB was not highly toxic to zebra fish. Zebra fish were all dead within $30 \mathrm{~min}$ in positive control with $1 \mathrm{ppm}$ Niclosamide while there were no dead in negative control with de-chlorinated water. The $\mathrm{LC}_{50}$ values of PFGB was $131.34 \mathrm{mg} \cdot \mathrm{L}^{-1}$ within $48 \mathrm{~h}$
(Figure 5). It is much higher than $\mathrm{LC}_{50}$ values of snails $\left(13.78 \mathrm{mg} \cdot \mathrm{L}^{-1}\right)$. That is to say, PFGB caused $50 \%$ mortality in snails but had no effect on zebra fish at the concentration of $13.78 \mathrm{mg} \cdot \mathrm{L}^{-1}$.

\section{Conclusion}

The results demonstrated that the fallen leaf of G. biloba might be an important molluscicides and molluscicidal active fraction was petroleum ether fraction of its ethanolic extract (PFGB). PFGB had significant molluscicidal activity against the snail $O$. hupensis and the molluscicidal activity was time and dose dependent. PFGB can also decrease the $\mathrm{Gn}$ and TPr content in 
snails' soft tissues and the decreasing rate were parallel to the molluscicidal activity. Meanwhile, PFGB was not highly toxic to zebra fish. Therefore, PFGB might be a potent molluscicides against $O$. hupensis. Nevertheless, isolation of the molluscicidal active substance from PFGB and the mechanism of snail death ask further study. On the other hand, G. biloba is widely distributed in China, which is suitable to live in moist environment. Hence, $G$. biloba is possible to plant on the beach of Yangtze River and its fallen leaf might become a natural and potential molluscicides to control the snails.

\section{ACKNOWLEDGMENTS}

Authors are grateful to Zhenjiang Center for Disease Control and Prevention, Jiangsu province, China for providing snail and authentication. We also thank Prof. You-sheng Liang (Jiangsu Institute of Schistosome Diseases, Jiangsu Province, China) for useful suggestions.

\section{REFERENCES}

Adedotun Adenusi A, Alexander Odaibo B (2008). Laboratory assessment of molluscicidal activity of crude aqueous and ethanolic extracts of Dalbergia sissoo plant parts against Biomphalaria pfeifferi. Travel. Med. Infectious. Disease., 6: 219-27.

Allen EJ, Victory Jr. HD (2003). Moderling and simulation of a schistosomiasis infection with biological control. Acta. Trop., 87: 25167.

Andrews P, Thyssen J, Lorke D (1983). The biology and toxicology of Molluscicides, Bayluscides. Pharmacol. Ther. 19: 245-95.

Barbara Ahlemeyer, Dagmar Selke, Christine Schaper, Susanne Klumpp, Josef Krieglstein (2001). Ginkgolic acids induce neuronal death and activate protein phosphatase type-2C. Eur. J. Pharmacol., 430: 1-7.

Bruce Diamond J (2000). Ginkgo biloba extract: Mechanisms and clinical indications. Arch. Phys. Med. Eehab., 81: 668-78.

Chen J, Han BX, Guo SB, Wang Y, He J, Zhou XK (2009). Molluscicidal activity against Oncomelania hupensis of endophyte JJ18 from Pseudolarix kaempferi Gord. Phcog. Res., 1: 421-27.

Chitsulo L, Engels D, Montresor A, Savioli L (2000). The global status of schistosomiasis and its control. Acta. Trop., 77: 41-51.

Engels D, Chitsulo L, Montresor A, Savioli L (2002). The global epidemiological of Schistosomiasis and new approaches to control and research. Acta. Trop., 82: 139-46.
Hong G, Dai YH, Liu PX, Shen X, Wei YY, Li G (2008). Advances in research on chemical constituents and pharmacological activities of Agrimonia pilosa. Pharm. Care., Res., 8: 362-66.

Ke WS, Yang JL, Meng Zh, Ma AN (2008). Evaluation of molluscicidal activities of Arisaema tubers extracts on the snail Oncomelania hupensis. Pestic. Biochem. Physiol., 92: 129-32.

Lena M, Goh, Philip Barlow J, Chee Yong S (2003). Examination of antioxidant activity of Ginkgo biloba leaf infusions. Food. Chem., 82: 275-82.

Liu YF, Peng Y, Liu FX (2006). Extraction of the active components of Cinnamomum camphora and Nerium indicum against Oncomelania hupensis. J. Hubei. Univ. Nat. Sci., 28: 81-83.

Muhammad Khalid Saeed, Yulin Deng, Rongji Dai, Wei Li, Yuhong Yu, Zafar lqbal (2010). Appraisal of antinociceptive and anti-inflammatory potential of extract and fractions from the leaf of Torreya grandis Fort Ex.Lindl. J. Ethnopharmacol., 127: 414- 18.

Pieri O, Goncalves JF, Sarquis O (1995). Repeated focal mollusciciding for snail control in sugar-cane area of northeast Brazil. Mem. Inst. Oswaldo Cruz. 90: 535-36.

Preetee Jaiswal, Singh DK (2008). Molluscicidal activity of Carica papaya and Areca catechu against the freshwater snail Lymnaea acuminate. Vet Parasitol., 152: 264-70.

Schäfer P, Rodríguez M, Just S, Ullrich T, Winkler K, Knes O (2006). The effect of Ginkgo biloba (EGb 761) on arteriosclerotic nanoplaque formation and size in a long-term clinical trial. Desalination. 191: 42631.

Schillaci D, Venturella F, Venuti F, Plescia F (2003). Antimicrobial and antiproliferative of Peucedanum nebrodense (Guss.) Strohl. J. Ethnopharmacol., 1: 99-101.

Tan QW, Wu ZJ, Ouyang MA (2008). Research progress in Chemical Constituents and Bioactivities of Ailanthus altissima. Nat. Prod. Res. Dev., 20:748-55.

Thanh Thuy Nguyen Tu, Sylvie Derenne, Claude Largeau, André Mariotti, Hervé Bocherens (2001). Evolution of the chemical composition of Ginkgo biloba external and internal Leaf lipids through senescence and litter formation. Org. Geochem., 32: 45-55.

WHO. Report of the WHO Expert Committee: The control of Schistosomiasis (WHO Technical Report Series); (1984). Nov 8-13; Geneva; 1985.

Yang XM, Chen SX, Xia L, Chen J (2008). Molluscicidal activity agains Oncomelania hupensis of Ginkgo biloba. Fitoterapia., 79: 250-54.

Zhou XN, Wang LY, Chen MG, Wu XH, Jiang QW, Chen XY (2005). The public health significance and control of Schistosomiasis in Chinathen and now. Acta. Trop., 96: 97-105. 